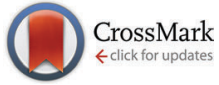

Cite this: New J. Chem., 2014, 38, 5096

DOI: $10.1039 / c 4 n j 90035 a$

www.rsc.org/njc

\section{Correction: A facile and efficient synthesis of} functionalized 4-oxo-2-(phenylimino)thiazolidin5-ylideneacetate derivatives via a $\mathrm{CuFe}_{2} \mathrm{O}_{4}$ magnetic nanoparticles catalyzed regioselective pathway

\author{
Gargi Pal, Sanjay Paul and Asish R. Das*
}

Correction for 'A facile and efficient synthesis of functionalized 4-oxo-2-(phenylimino)thiazolidin-5ylideneacetate derivatives via a $\mathrm{CuFe}_{2} \mathrm{O}_{4}$ magnetic nanoparticles catalyzed regioselective pathway' by Gargi Pal et al., New J. Chem., 2014, 38, 2787-2791.

The single-crystal X-ray crystallographic studies of products $\mathbf{4 e}$ and $\mathbf{4 f}$ indicate that the structures of the compounds (4a-l) in the manuscript and supporting information should be represented as:<smiles>[R2]OC(=O)/C=C1\S/C(=N/c2ccccc2)N([R])C1=O</smiles>

The authors apologise for the mistake. The supporting information was updated on 28th August 2014.

The Royal Society of Chemistry apologises for these errors and any consequent inconvenience to authors and readers. 